\title{
Pengendalian Persediaan Batubara Menggunakan Metode Economic Order Quantity (EOQ) (Studi Kasus : PT. Indah Kiat Pulp \& Paper tbk)
}

\author{
Denny Astrie Anggraini ${ }^{1)}$, Rudy ${ }^{2)}$ \\ Program Studi Teknik Industri Fakultas Teknik Universitas Muhammadiyah Riau \\ Jalan Tuanku Tambusai Ujung No. 1 Kota Pekanbaru Provinsi Riau \\ E-mail : dennyastrie@umri.ac.id, 170103070@ student.umri.ac.id
}

\begin{abstract}
PT. Indah Kiat Pulp and Paper Perawang Mill is one of the largest pulp and paper producing companies in Indonesia and even in Southeast Asia. This company produces its own energy for production purposes. Where this company has 12 Steam Power Plants (PLTU) with a boiler system. This Steam Power Plant (PLTU) uses several types of fuel, both biomass and fossil fuel types. The main fuel used is the type offossil coal. However, currently the coal inventory control process has not been carried out properly so that a lot of coal is piled up in the stockpile and causes coal to burn (Spontanous Comustion). In order not to cause losses to the company, the control of coal inventory must be carried out properly. One method that can be used is the Economic Order Quantity (EOQ) method for 12 periods (1 year) namely December 2020 November 2021. From the results of this inventory control, the number of economic orders for coal is 20,841 tons with a total of 107 orders. To avoid stockpiling or shortages, a safety stock is needed, namely 847,439 Tons, while reordering can be done when the coal stock in the stockpile is 522,155 Tons remaining. With maximum stock in stockpile is 868,820 Tons. The total cost for coal inventory that must be spent is Rp. 23,244,747.
\end{abstract}

Keywords : Coal, Inventory Control, Economic Order Quantity (EOQ)

\begin{abstract}
Abstrak
PT. Indah Kiat Pulp and Paper Perawang Mill merupakan salah satu perusahaan penghasil pulp dan kertas terbesar di Indonesia bahkan di Asia Tenggara. Perusahaan ini menghasilkan energi sendiri untuk keperluan produksi. Dimana perusahaan ini memiliki 12 Pembangkit Listrik Tenaga Uap (PLTU) yang bersistem boiler. Pembangkit Listrik Tenaga Uap (PLTU) ini menggunakan beberapa jenis bahan bakar, baik bahan bakar jenis biomassa dan juga jenis bahan bakar fosil. Bahan bakar utama yang digunakan adalah jenis fosil batubara. Namun saat ini proses pengendalian persediaan batubara belum dilakukan dengan baik sehingga batubara banyak tertumpuk di stockpile dan mengakibatkan batu bara terbakar (Spontanous Comustion). Agar tidak menimbulkan kerugian bagi perusahaan maka pengendalian persediaan batubara harus dilakukan dengan baik. Salah satu metode yang bisa digunakan yaitu metode Economic Order Quantity (EOQ) untuk 12 periode (1 tahun) yaitu Desember 2020 - November 2021. Dari hasil pengendalian persediaan ini diperoleh jumlah pemesanan ekonomis batubara adalah 20.841 Ton dengan jumlah pemesanan sebanyak 107 kali. Untuk menghindari stok yang menumpuk atau kekurangan maka diperlukan stok pengaman yaitu 847.439 Ton, sedangkan pemesanan kembali dapat dilakukan ketika stok batubara di stockpile tersisa 522.155 Ton. Dengan persediaan maksimum di stockpile adalah 868.820 Ton. Total biaya untuk persediaan batubara yang harus dikeluarkan adalah Rp. 23.244.747.
\end{abstract}

Kata kunci : Batubara, Pengendalian Persediaan, Economic Order Quantity (EOQ)

\section{Pendahuluan}

PT. Indah Kiat Pulp and Paper Perawang Mill merupakan salah satu perusahaan yang berada di Kabupaten Siak yang beralamat di Jalan Raya Minas - Perawang KM 26, Pinang Sebatang, Kecamatan tualang, Kabupaten Siak, Provinsi Riau 28653. Perusahaan ini merupakan perusahaan manufaktur yang memproduksi pulp dan kertas. Perusahaan ini salah satu anak perusahaan Asia Pulp and Paper (APP) Grup, yang termasuk sektor bisnis dari Sinarmas Grup.

Penelitian ini dilakukan di divisi energi (EGD). Divisi energi merupakan sektor penghasil energi listrik dan uap steam (uap) yang berfungsi 
untuk kebutuhan produksi dan kebutuhan non produksi. Selama penelitian dilakukan observasi lapangan yaitu dengan bertanya kepada pihak terkait mengenai data-data yang dibutuhkan untuk keberhasilan penelitian.

PT. Indah Kiat Pulp and Paper Perawang Mill merupakan salah satu perusahaan penghasil pulp dan kertas terbesar di Indonesia bahkan di Asia Tenggara. Perusahaan ini menghasilkan energi sendiri untuk keperluan produksi. Dimana perusahaan ini memiliki 12 Pembangkit Listrik Tenaga Uap (PLTU) yang bersistem boiler. Pembangkit Listrik Tenaga Uap (PLTU) ini menggunakan beberapa jenis bahan bakar, yaitu batubara, solar, cangkang sawit, tangkos sawit, fibre sawit, kulit kayu, MFO (Marine Fuel Oil) dan RCO (Rubber Compound Oil). Konsumsi bahan bakar sesuai dengan kebutuhan boiler, tetapi yang menjadi bahan baku utamanya adalah batubara, hal ini karena batubara memiliki cadangan yang banyak serta biaya produksinya murah. Batubara ini disuplai oleh beberapa vendor yang berasal dari berbagai daerah disumatera dengan jalur pengiriman via darat dan laut.

Data konsumsi dan penerimaan batubara selama 11 periode dapat dilihat pada gambar 1 . Pengendalian persediaan batubara perlu ditangani dengan baik, untuk meminimalisir bahkan menghilangkan kerugian. Karena jika tidak ditindak maka banyak dampak yang akan terjadi. Salah satu dampak tersebut adalah batubara akan terbakar dengan sendirinya dikarenakan stok yang terlalu lama tertumpuk di stokpile tidak digunakan dan terjadinya antrian yang banyak, karena tidak sesuainya konsumsi dengan permintaan batubara, serta stockpile menjadi penuh.

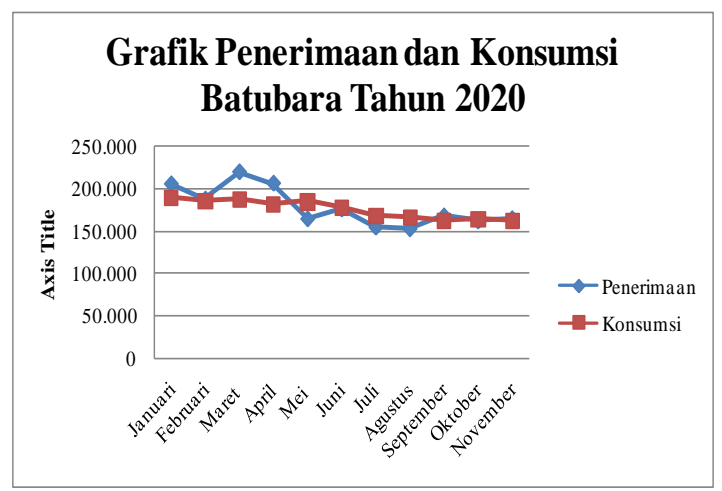

Gambar 1. Grafik Penerimaan dan Konsumsi Batubara Januari-November 2020

Oleh sebab itu diperlukan pengendalian persediaan batubara agar tercapainya persediaan yang efektif dan efisien, sehingga dapat meminimalisir kerugian bahkan menghilangkan kerugian dalam produksi energi. Perbaikan yang harus dilakukan perusahaan adalah mengendalikan jumlah pemesanan yang ekonomis dan banyaknya pemesanan, serta mengendalikan jumlah stok pengaman, pemesanaan kembali, jumlah maksimal batubara yang ada di stokpile, dan mengetahui total biaya yang diperlukan untuk persediaan batubara.

Metode yang cocok digunakan untuk mengendalikan persediaan ini adalah metode Economic Order Quantity (EOQ), karena metode ini merupakan metode yang efektif dan efisien sehingga sangat tepat digunakan untuk persediaan bahan material yang tingkat kebutuhannya banyak.

Menurut Gitosudarmo (2002:245) EOQ (Economical Order Quantity) adalah jumlah pembelian yang paling ekonomis yaitu dengan melakukan pembelian secara teratur sebesar EOQ itu maka perusahaan akan menanggung biaya-biaya pengadaan bahan yang minimal.

\section{$\mathrm{CONTOH}$ :}

Eqonomic Order Quantity adalah jumlah pembelian yang paling ekonomis yaitu dengan melakukan pembelian secara teratur sebesar EOQ itu maka perusahaan akan menanggung biaya-biaya pengadaan bahan yang minimal. [3]

Persediaan pengaman (Safety Stock) merupakan suatu persediaan yang dicadangankan sebagai pengaman dari kelangsungan proses produksi perusahaan. Persediaan pengaman diperlukan karena dalam kenyataannya jumlah bahan baku yang diperlukan untuk proses produksi tidak selalu tepat seperti yang direncakan.

Pemesanan kembali (Reorder Point) adalah saat atau waktu tertentu di mana perusahaan harus mengadakan pemesanan bahan baku kembali, sehingga datangnya pemesanan tersebut tepat dengan habisnya bahan baku yang dibeli, khususnya dengan menggunakan metode EOQ.

Persediaan Maksimal (Maximum Inventory) adalah jumlah maksimal yang berada di lokasi penyimpanan/gudang, sehingga kondisi gudang tidak menumpuk banyak dan berlebih.

Biaya Total Persediaan (Total Inventory Cost) adalah jumlah biaya persediaan yang harus dikeluarkan oleh perusahaan, biaya tersebut terdiri dari penjumlahan biaya pemesanan dengan biaya pemeliharaan atau persediaan. Biaya Total Persediaan digunakan sejalan untuk pemesanan ekonomis/Economic Order Quantity (EOQ)

\section{Metodologi Penelitian}

Penelitian ini dilakukan di Divisi Energi (EGD) pada unit Solid Fuel Material PT. Indah Kiat Pulp and Paper Perawang. Objek yang diamati adalah mengenai persediaan batubara, baik itu jumlah pemesanan, serta dampak yang terjadi pada sistem lama dalam mengendalikan persediaan batubara. 
Data yang digunakan pada penelitian ini adalah data historis penerimaan dan konsumsi batubara pada 24 periode ( 24 bulan yang lalu), dan data biaya-biaya yang diperlukan yaitu biaya pemesanan, biaya penyimpanan, dan biaya pembelian batubara.

Tahapan yang dilakukan pada penelitian ini yaitu :

a. Melakukan Peramalan Permintaan

Pada tahap ini melakukan peramalan permintaan batubara untuk 12 periode (12 bulan) kedepannya, dengan berdasarkan acuan data historis, agar dapat mengetahui jumlah batubara yang akan dipesan untuk kedepannya. Peramalan dilakukan menggunakan aplikasi Winqsb.

b. Mengklasifikasikan Jenis-Jenis Biaya

g. Melakukan Perhitungan Biaya Total Persediaan

h. Pada perhitungan ini dibutuhkan data biaya penyimpanan, biaya pemesanan dan hasil peramalan batubara.

\section{Hasil dan Pemabahasan}

Berdasarkan metode pada penelitian ini maka didapatkan hasil berdasarkan langkah-langkah yang digunakan, yaitu :

\subsection{Peramalan Permintaan Batubara}

Pada peramalan ini menggunakan data historis konsumsi batubara, pemalan menggunakan aplikasi Winqsb. Metode yang digunakan berdasarkan bentuk plot data historis, sehingga didapatkan 3 metode yang cocok yaitu sebagai berikut :

1. Metode Single Exponential Smoothing dengan nilai alpha yaitu 0,3, 0,5, dan 0,9.

2. Metode Double Exponential Smoothing dengan nilai alpha yaitu $0,3,0,5$, dan 0,9 .

3. Metode Regresi Linear (Linear Regression)

Setelah dilakukan peramalan menggunakan 3 metode diatas dengan menggunakan software win qsb, maka dilakukan pemilihan metode terbaik berdasarkan tingkat kesalahan berdasarkan nilai MSE terkecil, sehingga metode terbaik yang terpilih adalah metode Double Exponential Smoothing $\alpha=$ 0,9 . Dengan hasil peramalan pada tabel 1 .

Tabel 1.

Hasil Peramalan Metode Double Exponential Smoothing $\alpha=$ 0,9
Pada tahap ini dilakukannya pengelompokan jenis biaya yang dibutuhkan untuk menghitung nilai EOQ, adapun jenis biaya tersebut adalah biaya penyimpanan selama setahun dan biaya untuk pemesanan batubara.

c. Melakukan Perhitungan Economic Order Quantity (EOQ)

Pada perhitungan ini membutuhkan data peramalan yang telah dilakukan.

d. Melakukan Perhitungan Stok Pengaman

Pada perhitungan ini membutuhkan data peramalan

e. Melakukan Perhitungan Pemesanan kembali Pada perhitungan ini membutuhkan data peramalan, dan stok pengaman.

f. Melakukan Perhitungan Persediaan Maksimal Pada perhitungan ini membutuhkan data stok pengaman dan data EOQ.

\begin{tabular}{|c|c|c|}
\hline No & Periode & Hasil Peramalan \\
\hline 1 & Desember 2020 & 162,7277 \\
\hline 2 & Januari 2021 & 162,7277 \\
\hline 3 & Februari 2021 & 162,7277 \\
\hline 4 & Maret 2021 & 162,7277 \\
\hline 5 & April 2021 & 162,7277 \\
\hline 6 & Mei 2021 & 162,7277 \\
\hline 7 & Juni 2021 & 162,7277 \\
\hline 8 & Juli 2021 & 162,7277 \\
\hline 9 & Agustus 2021 & 162,7277 \\
\hline 10 & September 2021 & 162,7277 \\
\hline 11 & Oktober 2021 & 162,7277 \\
\hline 12 & November 2021 & 162,7277 \\
\hline \multicolumn{2}{|r|}{ MSE } & 35,06601 \\
\hline & Alpha & 0,9 \\
\hline
\end{tabular}

Berdasarkan hasil diatas maka dapat dilihat bahwa total kebutuhan batubara untuk 12 periode (1tahun) adalah 1.952.736 Ton.

\subsection{Mengklasifikasikan Biaya Yang Dibutuhkan}

1. Biaya Pemesanan

Biaya pemesanan meliputi biaya administrasi dan biaya pengiriman yang mana ditanggung oleh kedua belah pihak (penjual dan pembeli). Biaya ini akan dikeluarkan disetiap pemesanan. Untuk biaya administrasi sebesar Rp.30.000 adalah biaya per pengiriman satu truk dengan muatan truk sekitar 30 ton. Jadi biaya untuk per tonnya adalah Rp.1000. Total biaya pemesanan batu bara terdapat pada tabel 2.

Tabel 2.

Biaya Pemesanan Batubara

\begin{tabular}{|lc|lr|ll|}
\hline \multicolumn{4}{|c|}{ Jenis Biaya } & \multirow{2}{*}{ Total Biaya } \\
\cline { 1 - 2 } Biaya Administrasi & \multicolumn{2}{|c|}{ Biaya Pengiriman } & & \\
\hline $\mathrm{Rp}$ & 1.000 & $\mathrm{Rp}$ & 95.000 & $\mathrm{Rp}$ & 96.000 \\
\hline
\end{tabular}

2. Biaya Penyimpanan

Biaya ini meliputi operasional penyimpanan serta biaya pengujian kualitas batubara yang baru 
datang dan akan disimpan di stockpile, pengujian ini dilakukan oleh pihak independen surveyor. Total biaya penyimpanan terdapat pada tabel 3 .

Tabel 3.

Biaya Pemesanan Batubara

\begin{tabular}{|c|l|lr|}
\hline No & \multicolumn{2}{|c|}{ Jenis Biaya } & Biaya (Rupiah)/Tahun \\
\hline 1 & Biaya Tenaga Kerja (5 Orang) & $\mathrm{Rp}$ & 363.240 .000 \\
\hline 2 & Biaya Alat Loader (1 Unit) & $\mathrm{Rp}$ & 360.000 .000 \\
\hline 3 & Biaya Sewa Excavator (1 Unit) & $\mathrm{Rp}$ & 300.000 .000 \\
\hline 4 & Biaya Pengecekan Kualitas (Independent Lab) & $\mathrm{Rp}$ & 1.171 .641 .600 \\
\hline \multicolumn{2}{|c|}{ Total } & $\mathrm{Rp}$ & 2.194 .881 .600 \\
\hline
\end{tabular}

Berdasarkan data diatas maka didapat biaya penyimpanan batubara per satuannya (perton), yaitu sebagai berikut :

$$
\begin{aligned}
\text { Biaya } & =\frac{\text { Biaya Penyimpanan Pertahun }}{\text { Kebutuhan Batubara Pertahun }} \\
& =\frac{\text { Rp. } 2.194 .881 .600}{1.952 .736}=\text { Rp.1.124/Ton }
\end{aligned}
$$

Berdasarkan perhitungan biaya ini maka didapatlah biaya penyimpanan batubara persatuannya yaitu Rp. 1.124/Ton.

\subsection{Perhitungan Pemesanan Ekonomis Economic Order Quantity (EOQ)}

Dalam hal ini perhitungan EOQ menggunakan rumus dibawah ini:

$$
\mathrm{EOQ}=\sqrt{\frac{2 \mathrm{SD}}{\mathrm{H}}}
$$

Dimana:

$$
\begin{array}{ll}
\text { EOQ } & =\text { Jumlah pemesanan ekonomis (unit) } \\
\mathrm{S} & =\text { Biaya pemesanan perperiode } \\
\mathrm{D} & =\text { Tingkat kebutuhan perunit waktu } \\
& \quad \text { (unit/periode) } \\
\mathrm{H} & =\text { Biaya penyimpanan (rupiah/periode) }
\end{array}
$$

Sedangkan perhitungan frekuensi pemesanan, menggunakan rumus dibawah ini:

Dimana:

$$
\mathrm{F}=\frac{\mathrm{D}}{\mathrm{Q}}
$$

$\mathrm{F}=$ Banyaknya pemesanan (kali/periode)

$\mathrm{D}=$ Tingkat kebutuhan perunit waktu (unit/periode)

$\mathrm{Q}=$ Jumlah pemesanan (unit)

Adapun perhitungan EOQ pada batubara di PT Indah Kiat Pulp and Paper adalah sebagai berikut:

$$
\begin{aligned}
\text { EOQ } & =\sqrt{\frac{2 \mathrm{SD}}{\mathrm{H}}} \\
& =\sqrt{\frac{2 \times 96.000 \times 1.952 .736}{1.124}} \\
& =18.263 \text { Ton }
\end{aligned}
$$
sebesar:

Dengan frekuensi pemesanan batubara

$$
\mathrm{F}=\frac{\mathrm{D}}{\mathrm{Q}}
$$

$$
=\frac{1.952 .736}{18.263}=107 \text { kali pemesanan }
$$

Berdasarkan perhitungan EOQ diatas maka pemesanan ekonomis batubara adalah 18.263 Ton, dengan frekuensi kedatangan sebanyak 107 kali pemesanan.

\subsection{Perhitungan Stok Pengaman (Safety Stock)}

Dalam hal ini perhitungan safety stock menggunakan rumus dibawah ini:

Dimana:

$$
\text { Safety Stock }=\mathrm{Z} \text { x } \sigma
$$

Safety Stock $=$ Persediaan pengaman $($ Unit/tahun $)$ $\mathrm{Z}=$ Standar normal deviasi, dimana pada analisa ini digunakan batas toleransi 5\% $=1,64$.

$\sigma=$ Standar deviasi dari kebutuhan batubara

Untuk mencari standar deviasi digunakan rumus sebagai berikut:

$$
\sigma=\sqrt{\frac{\sum(\mathrm{X}-\overline{\mathrm{X}})^{2}}{\mathrm{n}}}
$$

Dimana:

$\sigma=$ Standar deviasi

$\mathrm{X}=$ Jumlah_kebutuhan (unit)

$\mathrm{X}=$ Rata-rata jumlah kebutuhan (unit)

$\mathrm{N}=$ Jumlah data (bulan)

Adapun perhitungan safety stock pada batubara di PT Indah Kiat Pulp and Papaer adalah sebagai berikut:

$$
\begin{aligned}
\sigma & =\sqrt{\frac{\sum(X-\bar{X})^{2}}{n}} \\
& =\sqrt{\frac{(1.790 .008)}{12}}=516.731
\end{aligned}
$$

Safety Stock $=\mathrm{Z} \times \sigma$

$$
\begin{aligned}
& =1,64 \times 516,731 \\
& =847.439 \text { Ton }
\end{aligned}
$$

Berdasarkan hasil hitungan diatas maka dapat dilihat bahwa nilai stok pengaman batubara tinggi yaitu 847.439 Ton, hal ini bisa mengakibatkan dampak pada batubara ketika dilakukan penyimpanan di area stockpile. Sehingga nilai stok pengaman yang baik untuk direkomendasikan adalah 100.000 Ton. Nilai ini merupakan asumsi untuk dari pihak perusahaan yang dapat memenuhi untuk kebutuhan 20 hari kedepan, yang bertujuan dapat menjaga kebutuhan ketika suplai dari pihak vendor mengalami masalah.

\subsection{Perhitungan Pemesanan Kembali (Reorder Point) \\ Dalam hal ini perhitungan ROP menggunakan} rumus dibawah ini:

$$
\mathrm{ROP}=\mathrm{D} \times \mathrm{L}+\mathrm{SS}
$$

Dimana:

ROP = Pemesanan kembali

$\mathrm{D}=$ Tingkat kebutuhan perbulan (unit)

$\mathrm{L} \quad=$ lead time (bulan) 
SS = safety stock (unit/tahun)

Adapun perhitungan pemesanan kembali pada batubara adalah sebagai berikut:

$$
\begin{aligned}
\mathrm{ROP} & =\mathrm{D} \times \mathrm{L}+\mathrm{SS} \\
& =\left(\frac{1.952 .736}{12}\right) \times\left(\frac{1}{30}\right)+100.000 \\
& =105.424 \text { Ton }
\end{aligned}
$$

Dengan penggunaan batubara secara terus menerus, maka akan menyebabkan persediaan semakin menipis, sehingga ketika persediaan sebanyak ROP yaitu 105.424 Ton, maka PT. Indah Kiat Pulp and Paper harus memesan kembali sebanyak EOQ yaitu 18.263 Ton.

\subsection{Perhitungan Stok Maksimal (Maximum Inventory)}

Dalam hal ini perhitungan persediaan maksimal menggunakan rumus dibawah ini:

Dimana:

Maximum inventory $=\mathrm{SS}+\mathrm{EOQ}$

Maximum inventory $=$ Persediaan maksimal (unit/tahun)

SS = safety stock (unit/tahun)

EOQ = Jumlah pemesanan ekonomis (unit)

Adapun perhitungan persediaan

maksimalpada batubara di PT Indah Kiat Pulp and

Paper adalah sebagai berikut:

Maximum inventory $=\mathrm{SS}+\mathrm{EOQ}$

$$
\begin{aligned}
& =100.000+18.263 \\
& =118.263 \text { Ton }
\end{aligned}
$$

Agar tidak terjadi penumpukan persediaan, sehingga persediaan maksimal untuk batubaraadalah 118.263 Ton.

\subsection{Perhitungan Biaya Total Persediaan (Total Inventory Cost)}

Dalam hal ini perhitungan maximum inventory menggunakan rumus dibawah ini:

$$
\mathrm{TIC}=\sqrt{2 \mathrm{DSH}}
$$

Dimana:

TIC = Biaya total persediaan (rupiah)

$\mathrm{D}=$ Tingkat kebutuhan perunit waktu (unit/Tahun)

$$
\begin{aligned}
\mathrm{S}= & \text { Biaya pemesanan (rupiah) } \\
\mathrm{H}= & \text { Biaya penyimpanan (rupiah/unit/tahun) } \\
& \text { Adapun perhitungan TIC pada batubara } \\
& \text { di PT Indah Kiat Pulp and Paper adalah } \\
& \text { sebagai berikut: }
\end{aligned}
$$

$\mathrm{TIC}=\sqrt{2 \mathrm{DSH}}$

$$
\begin{aligned}
& \text { TIC }=\sqrt{2 \times 1.952 .736 \times 96.000 \times 1.124} \\
& \text { TIC }=\text { Rp. } 20.528 .421
\end{aligned}
$$

Dari perhitungan diatas, didapatkan total biaya persediaan untuk batubara sebesar Rp. 20.528.421.

\section{Kesimpulan}

Setelah melakukan analisa terhadap pengendalian persediaan batubara menggunakan metode Economic Order Quantity (EOQ), maka dapat disimpulkan:

1. Dengan membandingkan 3 metode peramalan, didapatkan metode peramalan terbaik yaitu Single exponential smoothing dengan nilai $\alpha=$ 0,9. Maka di dapatkan hasil permintaan batubara selama 12 bulan sebesar 1.952 .736 Ton, dengan kebutuhan setiap bulannya berjumlah konstan yaitu 162.7277 Ton.

2. Jumlah pemesanan ekonomis (EOQ) untuk batubara yaitu 18.263 Ton, dengan jumlah pemesanan sebanyak 107 kali pemesanan.

3. Stok Pengaman yang harus dipersiapkan perusahaan adalah 100.000 Ton.

4. Pemesanan kembali batubara yang harus dilakukan perusahaan adalah sebanyak 18.263 Ton ketika stok batubara tersisa 105.424 Ton.

5. Persediaan maksimal batubara yang ada di stokpile adalah 118.263 Ton.

6. Biaya total persediaan untuk batubara adalah Rp. 20.528.421.

\section{Daftar Pustaka}

[1] Athary, Fuad. 2011. Perencanaan Persediaan Bahan Baku Kayu Gelondongan Dengan Metode Silver Meal (Studi kasus PT. Katingan Timber Celebes Makassar). Makassar. Universitas Hasanuddin Makassar.

[2] Lestari, Nurhayati. 2018. Pengendalian Pengadaan Bahan Bakar Menggunakan Metode Probabilistik Continuous Review System. Yogyakarta. Universitas Islam Indonesia.

[3] Nugraha, Yacoba, Eucharista, dan Suletra, I Wayan. 2017. Analisis Metode Peramalan Permintaan Terbaik Produk Oxycan Pada PT Samator Gresik. Surakarta. Program Studi Teknik Industri Fakultas Teknik. Universitas Sebelas Maret.

[4] Paduloh, Prasetyo, Rio. 2018. Analisis Pengendalian Persediaan Bahan Baku Plat Besi Industri Karoseri Menggunakan Metode EOQ (Studi Kasus Pada PT. Misitama). Jakarta. Universitas Bhayangkara Jakarta Raya.

[5] Prasetyawati, Meri dan Marfuah Umi, dan Wijaya Gofan. 2017. Usulan Pengendalian Kebutuhan Persediaan Menggunakan Metode Economic Order Quantity (EOQ) di PT. Indoreuck Utama Cabang Jakarta. Jakarta. Universitas Muhammadiyah Jakarta.

[6] Prasetyo, A. 2009. Analisa Peramalan Permintaan Produk Muffler Di PT. YMI, Tugas Akhir Fakultas Teknologi Industri, Universitas Mercu Buana. 
[7] Sitompul, Rio Oloan, 2011. Aplikasi Metode Economic Order Quantity (EOQ) Untuk Mengoptimalkan Persediaan Bahan Bakar Minyak (Studi Kasus PT. Kereta Api (Persero) Medan), Skripsi Fakultas Matematika Dan Ilmu Pengetahuan Alam, Universitas Sumatera Utara.

[8] Sulaiman, Fahmi dan Nanda. 2015. Pengendalian Persediaan Bahan Baku Dengan
Menggunakan Metode EOQ Pada UD. Adi Mabel. Medan Politeknik LP3I Medan. Jurnal Teknovasi.

[9] Topowijono, Yuliaana. 2016. Penerapan Model EOQ (Economic Order Quantity) Dalam Rangka Meminimumkan Biaya Persediaan Bahan Baku. Malang. Jurnal Administrasi Bisnis (JAB). 